Marquette University

e-Publications@Marquette

$11-1-2012$

\title{
Influence of Knee Flexion Angle and Age on Triceps Surae Muscle Fatigue During Heel Raises
}

Kim Hébert-Losier

University of Otago

Anthony G. Schneiders

University of Otago

José A. García

University of Otago

S. John Sullivan

University of Otago

Guy G. Simoneau

Marquette University, guy.simoneau@marquette.edu

Accepted version. Journal of Strength and Conditioning Research, Vol. 26, No. 11 (November 2012): 3124-3133. DOI. (C) 2012 Lippincott Williams \& Wilkins, Inc. Used with permission. 


\title{
Influence of Knee Flexion Angle and Age on Triceps Surae Muscle Activity during Heel Raises
}

\author{
Kim Hébert-Losier \\ Center for Physiotherapy Research, University of Otago \\ Dunedin, New Zealand \\ Anthony G. Schneiders \\ Center for Physiotherapy Research, University of Otago \\ Dunedin, New Zealand \\ José A. Garcia \\ Department of Preventive and Social Medicine \\ University of Otago \\ Dunedin, New Zealand \\ John S. Sullivan \\ Center for Physiotherapy Research, University of Otago \\ Dunedin, New Zealand \\ Guy G. Simoneau \\ Department of Physical Therapy, Marquette University \\ Milwaukee, WI
}

\begin{abstract}
Hébert-Losier, K, Schneiders, AG, García, JA, Sullivan, SJ, and Simoneau, GG. Influence of knee flexion angle and age on triceps surae muscle activity during heel raises. J Strength Cond Res 26(11): 3124-3133, 2012-Triceps surae and Achilles tendon injuries are frequent in sports medicine, particularly in middle-aged adults. Muscle imbalances and weakness are suggested to be involved in the etiology of these conditions,


with heel-raise testing often used to assess and treat triceps surae (TS) injuries. Although heel raises are recommended with the knee straight for gastrocnemius and bent for soleus (SOL), the extent of muscle selectivity in these positions is not clear. This study aimed to determine the influence of knee angle and age on TS muscle activity during heel raises. Forty-eight healthy men and women were recruited from a younger-aged (18-25 years) and middle-aged (35-45 years) population. All the subjects performed unilateral heel raises in $0^{\circ}$ and $45^{\circ}$ knee flexion (KF). Soleus, gastrocnemius medialis (GM) and gastrocnemius lateralis (GL) surface electromyography signals were processed to compute root-mean-square amplitudes, and data were analyzed using mixed-effects models and stepwise regression. The mean TS activity during heel raises was $23 \%$ of maximum voluntary isometric contraction when performed in $0^{\circ} \mathrm{KF}$ and $21 \%$ when in $45^{\circ}$. Amplitudes were significantly different between TS muscles $(p<0.001)$ and KF angles $(p<$ $0.001)$, with a significant interaction $(p<0.001)$. However, the age of the population did not influence the results $(p=0.193)$. The findings demonstrate that SOL activity was $4 \%$ greater when tested in $45^{\circ}$ compared with $0^{\circ} \mathrm{KF}$ and $5 \%$ lower in the GM and GL. The results are consistent with the recommended use of heel raises in select knee positions for assessing, training, and rehabilitating the SOL and gastrocnemius muscles; however, the 4-5\% documented change in activity might not be enough to significantly influence clinical outcome measures or muscle-specific benefits. Contrary to expectations, TS activity did not distinguish between middle-aged and younger-aged adults, despite the higher injury prevalence in middle age.

\section{Introduction}

Muscle and tendon injuries are common in sport participants. Muscle strains account for $10-55 \%$ of all injuries occurring during sporting events $(14,21)$, whereas $30-50 \%$ of overuse injuries are tendinous (22). The triceps surae (TS) muscles and Achilles tendon (AT) are reported as some of the most frequently injured structures in sport $(13,30)$, and specific clinical procedures are used to manage and prevent these conditions. For example, repetitive concentriceccentric heel-raise performances are employed to assess the TS and are included in exercise regimens to condition, rehabilitate, and in prevention of AT and TS injuries $(5,41)$.

Task specificity is an important concept in muscle rehabilitation, strengthening, and conditioning (11). For the TS muscles, heel raises are traditionally prescribed with $0^{\circ}$ knee flexion (KF) to target the gastrocnemius medialis (GM) and gastrocnemius lateralis (GL), and $45^{\circ} \mathrm{KF}$ for the soleus (SOL) $(1,20)$. The muscle bias associated with heel-raise repetitions is proposed to change with $\mathrm{KF}$ angle and is 
based on the structural anatomy, architecture, and muscle function of the TS muscles (40). To date, research also suggests that heel raises performed in different knee positions influences TS muscle specificity. For instance, Price et al. (32) used electromyography (EMG) in conjunction with magnetic resonance imaging techniques to investigate the TS muscles during dynamic plantar-flexion contractions at $3 \mathrm{KF}$ angles: $0^{\circ} \mathrm{KF}, 45^{\circ} \mathrm{KF}$, and $90^{\circ} \mathrm{KF}$. These authors reported decreasing $\mathrm{GM}$ and $\mathrm{GL}$ activities with increasing $\mathrm{SOL}$ activity as KF was increased. Although the latter findings support the use of different KF angles during heel raises to target the individual TS muscles, they derive from a non-weight-bearing task (sitting) and generalization to the conventionally prescribed heel-raise procedures in weight bearing (standing) is not appropriate. International research priorities include validating assessment procedures commonly used in musculoskeletal practice (37), and to date, there is currently limited evidence to justify using change in KF to direct heel-raise testing or conditioning toward the SOL or GM and GL. Therefore, the specificity of this task to the different TS muscles remains questionable.

Some musculoskeletal injuries are more frequent in youngeraged adults, but the prevalence of TS and AT injuries is reported to increase significantly after the mid-20s (31) and is highest in the fourth and fifth decades of life (23). Increase in age and muscle imbalances or weakness are recognized as predisposing factor to TS and AT pathogenesis (5), and it is important to identify risk factors or abnormal musculoskeletal functions to decrease the prevalence of injury. Surface EMG is a noninvasive technique often employed in clinical settings to explore muscle function (8) and to detect alterations, weakness, pathology, and potential injury risk factors (42). Whether an alteration in TS muscle function in middle-aged adults during heel raises can be captured through EMG has not yet been determined and may assist healthcare professionals and strength and conditioning coaches in further understanding injury prevalence, specifying risk factors, and establishing tailored management strategies specific to population age groups.

In consideration of the above clinical observations, the aim of this study was to investigate the influence of performing heel raises in 
$0^{\circ} \mathrm{KF}$ and $45^{\circ} \mathrm{KF}$ on the amount of SOL, GM, and $\mathrm{GL}$ activities, and the effect of age on the activity of the TS muscles. The formulated hypotheses were based on the traditional use of heel raises in select KF positions and its applications in musculoskeletal practice. More precisely, the hypothesis was that SOL activity would be greater during heel raises in $45^{\circ} \mathrm{KF}$ than in $0^{\circ} \mathrm{KF}$, with greater $\mathrm{GM}$ and $\mathrm{GL}$ activities in $0^{\circ} \mathrm{KF}$ compared with $45^{\circ} \mathrm{KF}$. In a second instance, it was speculated that TS activity from middle-aged individuals would be different from that of younger-aged adults in that the proportional contribution of each TS muscle toward the task would differ. An additional aim was to explore whether muscle activity differed between the concentric and eccentric plantar-flexion contractions of heel raises, considering their role in injury management and sports training. The hypothesis was that the amount of activity recorded during concentric contractions would be greater than that from eccentric contractions considering their lower physiological efficiency and reported lower activity levels at given workloads (7).

\section{Methods}

\section{Experimental Approach to the Problem}

This study used a prospective repeated-measures design and surface EMG techniques to investigate SOL, GM, and GL activities during heel raises. The root-mean-square (rms) amplitude variable can be derived from EMG signals to quantify the amount of muscle activity and is suggested to provide valuable information on muscle force generation and contribution to movement (27). The rms amplitude expressed as percent of maximum voluntary isometric contraction (MVIC) was hence chosen as the primary dependent variable. To investigate the muscle specificity of the heel-raise task with change in the KF angle, the 3 TS muscles (SOL, GM, and GL) were considered as separate entities and $2 \mathrm{KF}$ positions were chosen for testing. Heel raises in a knee straight position of $0^{\circ} \mathrm{KF}$ and in a knee bent position of $45^{\circ} \mathrm{KF}$ were selected to reflect those described in clinical practice and used for $\mathrm{GM}$ and $\mathrm{GL}$, and $\mathrm{SOL}$, respectively. In addition, the recruitment process targeted equal numbers of youngeraged (18-25 years) and middle-aged (35-45 years) individuals to explore whether TS muscle activity during heel raises was different 
between populations with a relatively low and high prevalence of AT and TS muscle pathologies, respectively. Finally, the concentric and eccentric components of a heel-raise cycle were delineated and used to explore differences between the 2 types of contractions per the additional research aim. In summary, the key dependent variable was the rms amplitude expressed as percentage of MVIC and the grouped independent variables inclusive of: 3 TS muscles, $2 \mathrm{KF}$ positions, 2 age groups, and 2 types of contractions.

\section{Subjects}

Forty-eight volunteers were recruited from the local community and took part in this study. Subject numbers for men and women were balanced to control for the potential confounding effect of gender on EMG signal. All the subjects were tested within a 2-month period and at a time of the day that was convenient to them. They were asked to refrain from strenuous activities for 24 hours before study participation. The individuals were included if they reported being in good general health and were excluded if they reported a current or previous injury to the AT or TS muscles, or a medical condition that could limit their ability to perform unilateral heel raises. All the subjects were provided with an information sheet of the study purpose and procedures and signed an informed consent document on the day of testing. The research was approved by the university's Institutional Review Board before subject recruitment and testing, which was held in an EMG-biomechanics laboratory. Baseline measures of the subjects were collected on the day of testing and included the Dunedin Footedness Inventory to determine lower-limb dominance (39) and the self-administered short-form International Physical Activity Questionnaire to capture physical activity levels and training backgrounds (6). None of the subjects were professional athletes. Baseline characteristics of the 48 subjects are summarized in Table 1.

\section{Procedures}

Each subject performed 1 trial of 10 unilateral heel raises with their dominant lower limb in both $0^{\circ} \mathrm{KF}$ and $45^{\circ} \mathrm{KF}$, with the aligned femur and tibia defining $0^{\circ} \mathrm{KF}$. The 2 selected $\mathrm{KF}$ angles were chosen 
based on common clinical musculoskeletal assessment procedures (20), strength training protocols prescribed in rehabilitation (1), and EMG studies of selective TS muscle activation in various KF positions (40). To account for the possible effects of testing sequence, the order of the $0^{\circ} \mathrm{KF}$ and $45^{\circ} \mathrm{KF}$ trials was block randomized according to age group and gender before the study. To position the subjects' knee in either $0^{\circ} \mathrm{KF}$ or $45^{\circ} \mathrm{KF}$, the principal investigator (K.H.-L.) followed standard goniometry guidelines (34) and used a long-arm goniometer (Fred Sammons Inc.; Brookfield, IL, USA). An TequipmentTequipment goniometer (Noraxon USA Inc.; Scottsdale, $A Z$, USA) was also fixed to the lateral aspect of the subjects' lower limb using double-sided tape with the fulcrum aligned with the kneejoint center, proximal arm with the greater trochanter, and distal arm with the lateral malleolus. The angular readings (degrees) from the electromechanical goniometer were displayed in real-time on a computer screen to the investigator who could then monitor KF angles and provide verbal information to subjects during heel-raise testing. If the KF angles were on average $> \pm 5^{\circ}$ of the target angle during testing, the subjects were rested for 5 minutes and asked to repeat the trial. A maximum of 3 trials was permitted per KF angle, and the one with the lowest absolute angular error was subsequently retained for further analysis. Illustrations of the $2 \mathrm{KF}$ angles and a complete heel-raise trial are provided in Figure 1.

A custom-made adjustable frame with an integrated dynamometer (Chatillon CSD200 Series Dynamometer, Ametek Inc.; Largo, FL, USA) was used for balance support. The subjects were allowed to place their index fingertips on the dynamometer handles positioned at shoulder height in front of them and use a maximum force equivalent to $2 \%$ of their body weight (36). The threshold value was individually established before heel-raise testing, and the subjects used the displayed force readings from the dynamometer to self-monitor the applied force. Stance foot placement was standardized by aligning the first metatarsal to a predetermined floor marking. Because TS muscle activity during dynamic tasks may be influenced by foot placement (35), the subjects served as their own controls by using their habitual unilateral weight-bearing stance for testing. The nontested lower limb was free in space in a self-selected position that allowed lower-limb clearance. An audible digital metronome (Sabine MT9000, Sabine Inc.; Alachua, FL, USA) was set 
at $120 \mathrm{~b} \cdot \mathrm{min}^{-1}$ to standardize the pace at 60 heel raises per minute; the heel lifting to maximal heel-raise height on the first beat and lowering to the floor on the second. One complete heel raise was defined by 2 consecutive heel-to-floor contacts and included a data point when the heel was at maximal height during that raise as identified in Figure 1. The chosen heel-raise parameters for balance support, body position, and pace were based on those most frequently cited in the literature (15) and used in a previous study (17). An overview of subjects' position and apparatus used for heelraise testing is provided in Figure 2 .

The subjects were instructed that testing required them to perform approximately 10 unilateral heel raises while maintaining the selected KF angle as precisely as possible. The subjects lifted the heel as high as possible during each heel raise and return the heel to the floor after each heel raise in pace with the metronome beats. They were reminded that the nontested limb should not contact the floor and to use the frame for balance support only. A countdown directed the subjects to start, and 15 seconds later, an audible signal advised the subjects to stop. The 15-second interval was selected to allow for the: initiation of the first heel raise; habituation of subjects to heel raise pace; and collection of data from 10 consecutive heel raises.

To describe, monitor, and relate the EMG data to heel-raise performance, kinematic data of lower-limb motion were acquired using a 3D motion analysis system incorporating 12 calibrated optoelectric cameras sampling at $100 \mathrm{~Hz}$ (Cortex version 1.1.4.368 software, Motion Analysis Corporation, Eagle EGL-500RT; Santa Rosa, CA, USA). Although a full series of retroreflective movement markers were used, only sagittal-plane data from select markers were extracted for the purpose of this study. The angle data recorded from the markers placed over the lateral malleolus, lateral femoral condyle, and greater trochanter were used to represent knee angles in degrees, and the distance between the marker positioned on the posterior aspect of the heel and the ground calibration markers was computed to provide a measure of heel-raise height in millimeters.

The EMG signals from SOL, GM, and GL were recorded via surface electrodes. Skin preparation and electrode positioning followed the Surface EMG for the Noninvasive Assessment of Muscles (19) and International Society of Electrophysiology and Kinesiology 
(26) recommendations. Subjects' skin was shaved, lightly abraded, and cleaned with alcohol swabs to reduce tissue impedance and electrode-to-skin artifacts. To correctly position the electrodes, all muscle bellies were first identified by palpation while under contraction. Electrode locations were specified and paired $\mathrm{Ag}-\mathrm{AgCl}$ gelled electrodes (Ambu Blue Sensor SP, AMBU A/S; Ballerup, Denmark) were subsequently placed on the non-contracted muscle bellies of (a) SOL, approximately two-thirds of the distance between the medial femoral condyle and medial malleolus; (b) GM, on the upper third of the posterior leg over the maximal muscle bulge on the medial side; and (c) GL, similar to GM, but on the lateral side of the leg. All paired electrodes were trimmed to allow interelectrode distances to be $<20 \mathrm{~mm}$ and were oriented parallel to the underlying muscle fibers. A single ground electrode was positioned over the tibial tuberosity. Skin impedance was measured using a multimeter (Fluke 70 series II, Tequipment. NET; Long Branch, NJ, USA) and the skin preparation process was repeated until all electrode sites were $<3,000$ [OMEGA]. The EMG signals were collected at a sampling rate of 3,000 Hz using a Noraxon TeleMyo 2400 T G2 and MyoResearch XP Master Edition Software package (Noraxon USA Inc., Scottsdale, AZ, USA). The telemetered system applied a band-pass filter of 10-500 $\mathrm{Hz}$; no notch $(50 / 60 \mathrm{~Hz}$ ) filters; input impedance >100 M[OMEGA]; a common mode rejection ratio $>100 \mathrm{~dB}$; a baseline $\mathrm{AC}$ noise $<1 \mu \mathrm{V}$ rms; an input range $\pm 3.5 \mathrm{mV}$; and a gain of 1,000 . The data were transmitted and digitized with 16-bit resolution for all analog inputs using a series of 30 data points for the zero correction of all acquired signals. A digital synchronization pulse was employed to allow for the combination and the synchronization of the collected EMG and kinematic data sets.

The experimental flow of the laboratory testing session was as follows: On the day of testing, the subjects signed an informed consent document and were then familiarized with testing equipment, procedures, and protocols. Baseline characteristics of the subjects were recorded, and lower-limb dominance was determined. The EMG recording system and the electromechanical goniometer were positioned, and signal quality was verified. If the acquired signals contained artifacts, the setup was adjusted until the quality of signals was appropriate. The MVIC data were captured for EMG normalization and heel-raise experimentation followed. 
The activity of the TS muscles during an MVIC was captured during an externally resisted unilateral heel raise performed to maximal height with the use of a Smith machine (Multipower M053 Technogym; Gambettola, Forli, Italy). A detailed account of the MVIC procedural methods employed has been published elsewhere (16). Three MVIC trials of 7 seconds, interspersed with an appropriate rest period of 2 minutes, were performed in each of the following KF positions: $0^{\circ} \mathrm{KF}$ (standing), $45^{\circ} \mathrm{KF}$ (standing), and $90^{\circ} \mathrm{KF}$ (sitting). The respective peak amplitudes captured from the SOL, GM, and GL during a stable 3 seconds from any 1 MVIC trial was extracted and used for subsequent normalization.

After MVIC data collection, the retroreflective movement markers were placed, and a static motion image was recorded to define the initial position of the markers. The standardized heel-raise instructions were provided, and the subjects performed a trial of heel raises in either $0^{\circ} \mathrm{KF}$ or $45^{\circ} \mathrm{KF}$ according to the preallocated random testing sequence. A 5-minute rest period was allocated, the instructions were reiterated, and the subjects performed another trial of 10 unilateral heel raises in the other KF position. During testing, the investigator provided consistent verbal feedback to ensure that all the instructions and parameters were followed and observed the angular readings provided by the electromechanical goniometer. Additional trials were performed if required.

\section{Data Processing}

The kinematic data collected during heel raises were referenced to the captured baseline static motion image. The first 2 heel raises completed were excluded to eliminate possible end-point errors, and the following 5 were extracted for further analyses $(17,35)$. A schematic summary of the data reduction process is illustrated in Figure 1 . The average knee angle maintained (degrees), maximum heel-raise height (millimeters), and mechanical work (joules) to complete a heel raise were computed to extract clinically meaningful biomechanical performance measures. Work was calculated by using the subject's weight (kilograms), average maximum heel-raise height, and gravitational acceleration $\left(9.81 \mathrm{~m} \cdot \mathrm{s}^{-2}\right)(41)$.

Each complete heel raise captured 1 full TS muscle contraction and included the concentric and eccentric components. The maximum 
height data point from each heel raise was used to separate the 2 types of contraction, where concentric occurred from the first heel-tofloor contact to the maximum heel-raise height data point and eccentric from the maximum heel-raise height data point to the second heel-to-floor contact (Figure 1).

The EMG signals of each extracted subset of 5 heel raises were processed to compute the SOL, GM, and GL rms amplitudes (microvolts) in 250-millisecond epochs. The derived rms amplitudes from each muscle were normalized to their respective peak amplitudes captured during MVIC procedures and expressed as percent of MVIC. For additional descriptive information regarding the overall activity of the TS muscles, the average percent activity of the SOL, GM, and GL from each trial was calculated to provide a numerical representation of the mean amount of average TS (ATS) muscle activity (29). For quality assurance of the surface EMG data muscle selectivity, a crosscorrelation processing technique was applied to the signals collected during MVIC and determined that crosstalk was minimal (8).

\section{Statistical Analyses}

Sample size determination was based on the assumption that the activity ratios between the SOL and GM would differ in the $2 \mathrm{KF}$ positions. Pilot study data and EMG data from research studies with similar aims $(40,43)$ were used to obtain estimates of means and variability in activity ratios in $0^{\circ} \mathrm{KF}$ and $45^{\circ} \mathrm{KF}$. Sample size requirements were calculated using standard 2 -tailed hypothesis equations, the derived estimates, an [alpha] $=0.05$ (5\% significance level), a [beta] $=0.10$ ( $90 \%$ power), critical values of the $t-$ distribution, and adjustments for $20 \%$ missing data (46). Calculations determined that a minimum sample of 44 subjects was required. To balance the study design and block randomize the order of testing according to age group and gender, sample size requirement was increased to 48 to have 12 men and 12 women in the 2 age groups.

The literature reports adequate to excellent reliability of the test measurements used in this study; hence, reliability data were not collected. The intraclass correlation coefficients reported in the literature for heel-raise performance range from 0.78 to $0.99(9,28)$, kinematic variables from similar motion analysis methods range from 
0.89 to 0.92 (12), and muscle activity data from the TS muscles during dynamic tasks from 0.82 to $0.99(25,44)$.

Mixed-effects models and stepwise regressions were used for the main analysis. This statistical approach allowed us to determine whether the variables of interest influenced the amount of muscle activity recorded during heel raises and to derive estimates of the difference between testing conditions. The mixed-effects model considered the influence of the individual TS muscles ( $S O L, G M, G L$ ), $\mathrm{KF}$ angles $\left(0^{\circ} \mathrm{KF}, 45^{\circ} \mathrm{KF}\right)$, and age groups (younger, middle) on rms signal amplitudes expressed as percent of MVIC. The model also considered all potential interaction effects. The model applied a generalized Gaussian distribution (Normal), adequately accounted for the repeated-measures design of the study by clustering withinsubject observations (random effect), and assumed an equal amount of correlation between subjects' measures (exchangeable correlation).

Nonsignificant effects were sequentially removed from the original model through stepwise regression according to the Bayesian information criterion, which penalizes a model according to its number of parameters (4). The nonsignificant 3-way and 2-way interactions were removed first. The final model from the stepwise analysis contained only effects that significantly influenced outcomes. The intercept and coefficients from the final regression were extracted and reported to provide values to estimate TS muscle EMG signal amplitudes during heel raises performed under a known set of conditions. The model intercept value provides an estimate of the amplitude compared to the defined conditional reference of SOL, $0^{\circ}$ $\mathrm{KF}$, and younger-age group. For instance, the KF coefficient from the final regression provides an estimate of the difference in amplitudes if heel raises are performed in $45^{\circ} \mathrm{KF}$ instead of $0^{\circ} \mathrm{KF}$ with all the other conditions remaining constant.

To see whether muscle activity differed between the concentric and eccentric contractions of heel raises, a similar rationale was employed. However, the mixed-effects model additionally included contraction (concentric, eccentric) and its interactions with KF, muscle, and age group. The concentric contraction was used as the reference in the final regression of the stepwise analysis, with coefficients estimating the difference in eccentric amplitudes compared to concentric. 
The probability level was set at 0.05 before all analyses, which were controlled for the repeated-measures design of the study. Because the influence from muscle was of threefold, Tukey Contrasts were used for multiple comparisons with the Westfall method adjusting the $95 \%$ confidence interval (CI) and $p$ values accordingly $(3,45)$. All data processing and analyses were completed using $R^{\mathrm{TM}}$ version 2.12.2 (R Foundation for Statistical Computing ${ }^{\mathrm{TM}}$; Vienna, Austria).

\section{Results}

A pooled descriptive summary of the biomechanical measures from heel-raise performances is provided in Table 2 . The mean knee angle maintained during $0^{\circ} \mathrm{KF}$ testing was $4.4^{\circ}$ and in $45^{\circ} \mathrm{KF}$ was $45.3^{\circ}$. The angles maintained were $\pm 5^{\circ}$ from the starting angle in both $\mathrm{KF}$ test positions.

A combined summary of the EMG data collected from all the subjects during heel raises is given in Table 3 . The mean signal amplitude in $0^{\circ} \mathrm{KF}$ compared with $45^{\circ} \mathrm{KF}$ was approximately $4 \%$ less for SOL and $5 \%$ more for the GM and GL. The GM was the most active muscle during $0^{\circ} \mathrm{KF}$ heel raises; $\mathrm{SOL}$, when in $45^{\circ} \mathrm{KF}$; with $\mathrm{GL}$ the least active in both positions. The mean amount of ATS activity was $2 \%$ higher in $0^{\circ} \mathrm{KF}(23 \%)$ compared with $45^{\circ} \mathrm{KF}(21 \%)$. Crosstalk was considered negligible because all absolute mean and peak values derived from the crosscorrelation of signals were $<0.30$ (8).

The main findings from the stepwise regression of EMG signal amplitudes during heel raises are given in Table 4. Amplitudes were significantly different between the SOL, GM, and GL muscles ( $p<$ 0.001 ), and in the 2 KF positions ( $p<0.001)$. The interaction between TS muscle and KF angle also significantly influenced amplitudes ( $p<0.001$ ). However, no significant differences between age groups were determined (95\%CI: $-0.9-4.2 ; p=0.193)$ with all other possible interactions having no significant influence on muscle activity during heel raises ( $p>=0.05$ ). The effects from age group and all their interactions were therefore dropped from the model during stepwise regression procedures. Because no significant differences in amplitudes were determined between age groups, detailed results are not included. 
The mixed-effects model used to derive coefficients for estimating amplitudes considered: muscle, $\mathrm{KF}$, and the interaction between muscle and KF. As shown in Table 4, the difference in amplitudes amongst the TS muscles during $0^{\circ} \mathrm{KF}$ heel raises was only significant when comparing GL to $G M(p=0.018)$ and not when comparing GM or GL with SOL ( $p>0.142$ ). The opposite was evidenced in $45^{\circ} \mathrm{KF}$ where the difference in amplitudes was not significant between $G L$ and $G M(p=0.097)$ but was when comparing the SOL with GM ( $p<0.001)$ or $G L(p<0.001)$. A visual representation of these results is provided in Figure 3 with the top third (KF on muscle) illustrating that the effect of change in the knee angle on SOL amplitude was different from its effect on GM and GL amplitudes. The mean and $95 \% \mathrm{CI}$ error bar of the difference in SOL amplitude do not overlap with the ones from the GM or GL. In contrast, the effect of change in the KF position on the GM and GL is similar as indicates their overlapping 95\%CI error bars.

The amount of TS muscle activity during heel raises can be estimated for an individual by using the values given in Table 4 . To estimate $\mathrm{GM}$ amplitude during $45^{\circ} \mathrm{KF}$ heel raises, the following rationale can be employed referencing the values from top to bottom of Table 4: (a) the model intercept (23.4\%) represents the activity of $\mathrm{SOL}$ in $0^{\circ} \mathrm{KF}$; (b) the influence of $\mathrm{KF}$ on SOL (3.6\%) considers that testing is in $45^{\circ} \mathrm{KF}$ and not $0^{\circ} \mathrm{KF}$; and (c) the influence of muscle in $45^{\circ} \mathrm{KF}(-7.4 \%)$ takes into account that the estimate is for the GM and not for the SOL. Therefore, the equation estimates a GM amplitude of $23.4+3.6-7.4 \%=19.6 \%$ during heel raises in $45^{\circ} \mathrm{KF}$. The final estimate corresponds to the sampled cohort mean value given in Table 2 and is applicable to both younger and middle-aged adults.

The secondary analysis determined that EMG amplitudes were in general $2.3 \%$ greater during eccentric contractions of heel raises compared with concentric (95\% CI: 0.8-3.7; $\mathrm{p}=0.002)$. The type of contraction did not interact with any of the other effects considered ( $p$ $>=0.05$ ), indicating that the amplitudes during concentric and eccentric contractions were not significantly different between the 3 TS muscles, 2 KF positions, and 2 age groups. Therefore, only a descriptive summary of amplitudes specific to concentric and eccentric contractions is provided as a supplementary file (Supplementary Table 2). 
NOT THE PUBLISHED VERSION; this is the author's final, peer-reviewed manuscript. The published version may be accessed by following the link in the citation at the bottom of the page.

\section{Discussion}

Understanding TS muscle activity during heel-raise performance in specific KF angles has important clinical implications in the assessment and rehabilitation of lower-limb injuries. The findings of this research generally support the common muscle-selective use of heel raises and accept the primary research hypothesis: SOL was more active in $45^{\circ} \mathrm{KF}$ than in $0^{\circ} \mathrm{KF}$, and vice versa for GM and GL. However, it is not clear whether the reported changes in amplitudes are clinically meaningful or large enough to influence the TS muscle selectivity during heel-raise testing, rehabilitation, or conditioning. Moreover, the differences in TS activity between middle-aged and younger-aged individuals were anticipated, but none were observed and the study hypothesis could not be accepted. No relationship between TS activity and injury risk based on age group can be established from these study results. Furthermore, the findings demonstrated greater amounts of TS activity during eccentric rather than concentric plantar-flexion contractions, which also contrasted with the working research hypothesis. Implications from the study findings are sequentially addressed from KF angles to age groups to concentric-eccentric contractions.

This study reports the mean differences in the SOL, GM, and GL amplitudes during heel raises that ranged from 3.6 to $5.5 \%$ when the KF angles were changed. Previous studies report that the differences in amplitudes that are $<=5 \%$ of an MVIC are not likely to influence clinical outcomes or rehabilitation (38), whereas a $20 \%$ variation in amplitudes or more corresponds to a quantifiable change in function and muscle performance scores (2). Based on these reports, the current findings on the influence of KF angle on TS muscle activity are not of clinical significance. The highest mean variation between testing angles in a given muscle was 5.5\% (GM) and between 2 muscles was $9.1 \%$ (GM and SOL). This suggests that coaches, trainers, and healthcare professionals may choose either $0^{\circ} \mathrm{KF}$ or $45^{\circ}$ KF to assess, train, or rehabilitate SOL, GM, and GL by heel-raise repetitions and expect to have similar clinical benefits and TS activity levels at both angles.

However, although a change in KF angle may have a limited clinical effect with respect to TS muscle activity during heel raises, the findings indicate that it might with regard to other biomechanical 
characteristics and functional requirements. For instance, slightly greater ATS muscle activity, mechanical work per heel raise, and heel-raise height were noted in $0^{\circ} \mathrm{KF}$ compared with $45^{\circ} \mathrm{KF}$.

According to a previous work (10), these changes in performance are most likely associated with variations in AT moment arm, TS muscle leverage, and plantar-flexion torque rather than in selective TS muscle activity. These biomechanical alterations between KF positions may lead to distinct structural loading patterns during heel raises, which is an important factor during rehabilitation (33). It appears more appropriate for clinicians to perceive heel raises in select KF positions as influencing the architectural features, fascicle behaviors, contributing muscle fibers, and loading patterns of the TS muscles and $\mathrm{AT}$ rather than targeting the $\mathrm{SOL}$ in $45^{\circ} \mathrm{KF}$ and the gastrocnemius in $0^{\circ} \mathrm{KF}$.

In contrast to expectations, the age groups documented to have a low (18-25 years) and high (35-45 years) prevalence of AT and TS injuries showed no differences in the activity amplitudes and individual contributions of the SOL, GM, and GL to heel-raise performances. These findings suggest that, in asymptomatic individuals, TS muscle activity quantified by surface EMG is not likely to identify middle-aged individuals during repeated heel raises despite the high prevalence of injuries reported in this population (23). The results do not support the use of EMG for this purpose in clinical practice. More plausible rationales of the higher prevalence include age-related degeneration, degree of tissue compliance, morphologic and histological compositions, and muscle timing or synchronization.

Our study identified higher levels of activity during eccentric compared with concentric heel-raise contractions, contradicting our initial research hypothesis. Determining the significance of these results is difficult considering that the $2 \%$ difference has a limited clinical value and that research comparing concentric and eccentric contractions provide contrasting results $(18,33)$. Omitting differences in the EMG methodological procedures, the variable findings in the literature are most likely related to the parameters dictating heelraise performance, for instance, pace. Henriksen et al. (18) reported higher concentric compared with eccentric activity when subjects performed 1 heel raise every 6.6 seconds. This study found 1 ower concentric than eccentric activity when using a quicker cadence. 
Faster heel raises might further rely on the storage and release of elastic energy of the stretch-shortening cycle, which is characterized by low concentric activity and shown in other EMG investigations (24). This highlights how change in any given parameter can influence muscle performance measures, which needs to be carefully considered during clinical assessment and exercise prescription.

There are always certain methodological considerations with all research projects. This study used surface EMG that is, at best, only quasispecific to deep and overlaid muscles such as the TS (8). However, we are confident that the data are as representative of SOL, $\mathrm{GM}$, and GL as permitted given that rigorous methodological EMG procedures were followed and crosscorrelation analyses confirmed minimal crosstalk. Surface EMG has the advantage of providing a global functional representation of muscles, is not limited to a few motor units, and is promoted for use in clinical practice (7). Furthermore, the balanced design of this study, with its equal numbers of male and female participants in 2 distinct age groups, makes the study methodologically robust; especially when taking into account its relatively large sample size compared with EMG studies of a similar design $(18,33)$.

\section{Practical Applications}

Heel raises are frequently used for the clinical management and conditioning of the TS muscles and AT and recommended in $0^{\circ} \mathrm{KF}$ and $45^{\circ} \mathrm{KF}$ for $\mathrm{GM}$ and $\mathrm{GL}$, and $\mathrm{SOL}$, respectively $(1,20)$. The SOL, $\mathrm{GM}$, and $\mathrm{GL}$ were $4-5 \%$ more active in their respective recommended $\mathrm{KF}$ angles, which is consistent with common musculoskeletal assessment and training protocols. However, the extent of variation might be too small to imply or influence TS muscle selectivity during heel raises, which is consistent with earlier work indicating no differences in total heel-raise numbers completed in different KF positions (17). In general, the 3 muscles are clinically considered to be just as active with the knee straight as bent, which implies that either position is appropriate for targeting SOL, GM, or GL activities in clinical practice. This suggests that using just $1 \mathrm{KF}$ position may increase the overall clinical efficiency of the heel-raise task without significantly decreasing its efficacy in regards to specific TS muscle activity. The influence of knee angles on TS muscle fatigue during 
heel raises in the 2 traditionally employed KF angles, and with different amounts of resistance, could also be investigated to justify the continued use of repeated heel-raises in select knee angles for muscle-selective purposes in sports medicine and rehabilitation.

\section{Acknowledgments}

The authors acknowledge the grant funding support that was provided by the Mark Steptoe Memorial Trust Research Grant-In-Aid from the School of Physiotherapy, University of Otago, Dunedin, New Zealand. No other grant funding was sought for the purpose of this research project. There are no conflicts of interest to declare.

\section{References}

1. Alfredson $\mathrm{H}$, Cook JL. Pain in the Achilles Region. In: Clinical Sports Medicine. Brukner P., Khan K., eds. Roseville East, New South Wales: McGraw-Hill Book Company Australia, 2006. pp. 590-611.

2. Bellew JW, Frilot CF, Busch SC, Lamothe TV, Ozane CJ. Facilitating activation of the peroneus longus: Electromyographic analysis of exercises consistent with biomechanical function. J Strength Cond Res 24: 442-446, 2010.

3. Bretz F, Hothorn T, Westfall P. Multiple Comparisons Using R. Boca Rato, FL: Taylor and Francis Group, 2010.

4. Burnham KP, Anderson DR. Model Selection and Multi-Model Inference: A Practical Information-Theoretic Approach. London, United Kingdom: Springer London Limited, 2010.

5. Carcia CR, Martin RL, Houck J, Wukich DK. Achilles pain, stiffness, and muscle power deficits: Achilles tendinitis. J Orthop Sports Phys Ther 40: A1-A26, 2010.

6. Craig $C L$, Marshall $A L$, Sjöström M, Bauman $A E$, Booth $M L$, Ainsworth $B E$, Pratt M, Ekelund ULF, Yngve A, Sallis JF, Oja P. International Physical Activity Questionnaire: 12-country reliability and validity. Med Sci Sports Exerc 35: 1381-1395, 2003.

7. Cram JR, Kasman GS. Introduction to Surface Electromyography. Frederick, MD: Aspen Publishers, 1998.

8. de Luca CJ. The use of surface electromyography in biomechanics. J Appl Biomech 13: 135-163, 1997. 
NOT THE PUBLISHED VERSION; this is the author's final, peer-reviewed manuscript. The published version may be accessed by following the link in the citation at the bottom of the page.

9. Dennis RJ, Finch CF, Elliott BC, Farhart PJ. The reliability of musculoskeletal screening tests used in cricket. Phys Ther Sport 9: 25-33, 2008.

10. Finni T, Hodgson JA, Lai AM, Edgerton VR, Sinha S. Nonuniform strain of human soleus aponeurosis-tendon complex during submaximal voluntary contractions in vivo. J Appl Physiol 95: 829-837, 2003.

11. Fleck SJ, Kraemer WJ. Designing Resistance Training Programs. Champaign, IL: Human Kinetics, 1997.

12. Ford KR, Myer GD, Hewett TE. Valgus knee motion during landing in high school female and male basketball players. Med Sci Sports Exerc 35: 1745-1750, 2003.

13. Fuller CW, Laborde F, Leather RJ, Molloy MG. International Rugby Board Rugby World Cup 2007 injury surveillance study. Br J Sports Med 42: 452-459, 2008.

14. Garrett WE Jr. Muscle strain injuries. Am J Sports Med 24: S2-8, 1996.

15. Hébert-Losier K, Newsham-West RJ, Schneiders AG, Sullivan SJ. Raising the standards of the calf-raise test: A systematic review. J Sci Med Sport 12: 594-602, 2009.

16. Hébert-Losier K, Schneiders AG, García JA, Sullivan SJ, Simoneau GG. Peak triceps surae muscle activity is not specific to knee flexion angles during MVIC. J Electromyogr Kinesiol 21: 819-826, 2011.

17. Hébert-Losier K, Schneiders AG, Sullivan SJ, Newsham-West RJ, García JA, Simoneau GG. Analysis of knee flexion angles during two clinical versions of the heel-raise test to assess soleus and gastrocnemius function. J Orthop Sports Phys Ther 41: 505-513, 2011.

18. Henriksen M, Aaboe J, Bliddal H, Langberg $\mathrm{H}$. Biomechanical characteristics of the eccentric Achilles tendon exercise. J Biomech 42: 2702-2707, 2009.

19. Hermens HJ, Freriks B, Merletti R, Hagg G, Stegeman D, Blok J, Rau G, Disselhorst-Klug C. SENIAM 8: European Recommendations for Surface Electromyography, Deliverable of the SENIAM Project. Enschede, The Netherlands: Roessingh Research and Development, 1999.

20. Hislop HJ, Montgomery J. Daniels \& Worthingham's Muscle Testing. St. Louis, MO: Saunders Elsevier, 2007.

21. Järvinen MJ, Lehto MUK. The effects of early mobilisation and immobilisation on the healing process following muscle injuries. Sports Med 15: 78-89, 1993.

Journal of Strength and Conditioning Research, Vol. 26, No. 11 (November 2012): pg. 3134-3147. DOI. This article is (C) Lippincott Williams \& Wilkins, Inc. and permission has been granted for this version to appear in ePublications@Marquette. Lippincott Williams \& Wilkins, Inc. does not grant permission for this article to be further copied/distributed or hosted elsewhere without the express permission from Lippincott Williams \& Wilkins, Inc. 
NOT THE PUBLISHED VERSION; this is the author's final, peer-reviewed manuscript. The published version may be

accessed by following the link in the citation at the bottom of the page.

22. Järvinen $T A H$, Kannus $P$, Maffulli N, Khan KM. Achilles tendon disorders: Etiology and epidemiology. Foot Ankle Clin 10: 255-266, 2005.

23. Khan RJ, Smith RLC. Surgical interventions for treating acute Achilles tendon ruptures. Cochrane Database Syst Rev 9: 1-54, 2010.

24. Komi PV. Stretch-shortening cycle: A powerful model to study normal and fatigued muscle. J Biomech 33: 1197-1206, 2000.

25. Laplaud D, Hug F, Grélot L. Reproducibility of eight lower limb muscles activity level in the course of an incremental pedaling exercise. J Electromyogr Kinesiol 16: 158-166, 2006.

26. Merletti R, di Torino P. Standards for reporting EMG data. J Electromyogr Kinesiol 9: III-IV, 1999.

27. Merletti R, Parker P. Electromyography: Physiology, Engineering, and Noninvasive Applications. Hoboken, NJ: IEEE/John Wiley \& Sons, 2004.

28. Möller M, Lind K, Styf J, Karlsson J. The reliability of isokinetic testing of the ankle joint and a heel-raise test for endurance. Knee Surg Sports Traumatol Arthrosc 13: 60-71, 2005.

29. Oksa J, Rintamäki H, Mäkinen T, Martikkala V, Rusko H. EMG-activity and muscular performance of lower leg during stretch-shortening cycle after cooling. Acta Physiol Scand 157: 71-78, 1996.

30. Orchard J, Best TM, Verrall GM. Return to play following muscle strains. Clin J Sport Med 15: 436-441, 2005.

31. Orchard JW. Intrinsic and extrinsic risk factors for muscle strains in Australian football. Am J Sports Med 29: 300-303, 2001.

32. Price TB, Kamen G, Damon BM, Knight CA, Applegate B, Gore JC, Eward $\mathrm{K}$, Signorile JF. Comparison of MRI with EMG to study muscle activity associated with dynamic plantar flexion. Magn Reson Imaging 21: 853-861, 2003.

33. Rees JD, Lichtwark GA, Wolman RL, Wilson AM. The mechanism for efficacy of eccentric loading in Achilles tendon injury; an in vivo study in humans. Rheumatology (Oxford) 47: 1493-1497, 2008.

34. Reese NB, Bandy WD, Yates C, Morris MA. Joint Range of Motion and Muscle Length Testing. St. Louis, MO: Saunders/Elsevier, 2010.

35. Riemann BL, Limbaugh GK, Eitner JD, Lefavi RG. Medial and lateral gastrocnemius activation differences during heel-raise exercise with three different foot positions. J Strength Cond Res 25: 634-639, 2011.

Journal of Strength and Conditioning Research, Vol. 26, No. 11 (November 2012): pg. 3134-3147. DOI. This article is (c) Lippincott Williams \& Wilkins, Inc. and permission has been granted for this version to appear in e-

Publications@Marquette. Lippincott Williams \& Wilkins, Inc. does not grant permission for this article to be further copied/distributed or hosted elsewhere without the express permission from Lippincott Williams \& Wilkins, Inc. 
NOT THE PUBLISHED VERSION; this is the author's final, peer-reviewed manuscript. The published version may be accessed by following the link in the citation at the bottom of the page.

36. Ross MD, Fontenot EG. Test-retest reliability of the standing heel-rise test. J Sport Rehabil 9: 117-123, 2000.

37. Rushton A, Moore A. International identification of research priorities for postgraduate theses in musculoskeletal physiotherapy using a modified Delphi technique. Man Ther 15: 142-148, 2010.

38. Ryan CG, Rowe PJ. An electromyographical study to investigate the effects of patellar taping on the vastus medialis/vastus lateralis ratio in asymptomatic participants. Physiother Theory Pract 22: 309-315, 2006.

39. Schneiders AG, Sullivan SJ, O'Malley KJ, Clarke SV, Knappstein SA, Taylor $L$. A valid and reliable clinical determination of footedness. Phys Med Rehabil 2: 835-841, 2010.

40. Signorile JE, Applegate B, Duque M, Cole N, Zink A. Selective recruitment of the triceps surae muscles with changes in knee angle. J Strength Cond Res 16: 433-439, 2002.

41. Silbernagel KG, Nilsson-Helander K, Thomeé R, Eriksson BI, Karlsson J. A new measurement of heel-rise endurance with the ability to detect functional deficits in patients with Achilles tendon rupture. Knee Surg Sports Traumatol Arthrosc 18: 258-264, 2010.

42. Valderrabano V, Nigg BM, Hintermann B, Goepfert B, Dick W, Frank CB, Herzog $W$, von Tscharner $V$. Muscular lower leg asymmetry in middleaged people. Foot Ankle Int 28: 242-249, 2007.

43. Wakahara $T$, Kanehisa $H$, Kawakami $Y$, Fukunaga $T$. Fascicle behavior of medial gastrocnemius muscle in extended and flexed knee positions. J Biomech 40: 2291-2298, 2007.

44. Wallmann HW, Mercer JA, Landers MR. Surface electromyographic assessment of the effect of dynamic activity and dynamic activity with static stretching of the gastrocnemius on vertical jump performance. J Strength Cond Res 22: 787-793, 2008.

45. Westfall PH, Johnson WO, Utts JM. A bayesian perspective on the bonferroni adjustment. Biometrika 84: 419-427, 1997.

46. Zar JH. Biostatistical Analysis. Upper Saddle River, NJ: Prentice Hall, 1999.

Key Words: electromyography; lower limb; ankle plantar flexion; clinical assessment; biomechanics

Journal of Strength and Conditioning Research, Vol. 26, No. 11 (November 2012): pg. 3134-3147. DOI. This article is (c) Lippincott Williams \& Wilkins, Inc. and permission has been granted for this version to appear in e-

Publications@Marquette. Lippincott Williams \& Wilkins, Inc. does not grant permission for this article to be further copied/distributed or hosted elsewhere without the express permission from Lippincott Williams \& Wilkins, Inc. 
NOT THE PUBLISHED VERSION; this is the author's final, peer-reviewed manuscript. The published version may be accessed by following the link in the citation at the bottom of the page.

\section{Image Gallery}

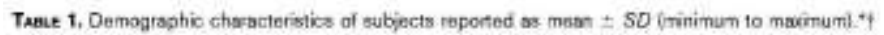

\begin{tabular}{|c|c|c|c|c|c|}
\hline \multirow[b]{3}{*}{ Characteristic: } & \multicolumn{5}{|c|}{ Subjocts } \\
\hline & \multicolumn{2}{|c|}{ Mals } & \multicolumn{2}{|c|}{ Formsien } & \multirow{2}{*}{$\frac{A 3}{(n-4 \mathrm{~B})}$} \\
\hline & $Y A$ in - 12) & $M A(n-12)$ & $Y A[n-12]$ & MA $(s-12)$ & \\
\hline Age $(y)$ & $\begin{array}{l}22.4=1.8 \\
(12.2-25.5)\end{array}$ & $\begin{array}{l}41.1=3.1 \\
(35.2-45.0)\end{array}$ & $\begin{array}{l}22.7 \pm 2.0 \\
(20.0-25.7)\end{array}$ & $\begin{array}{l}41.5=3.4 \\
(36.8-45.8)\end{array}$ & $\begin{array}{l}31.2 \pm 0.8 \\
\mid 12.2 \times 45.8\}\end{array}$ \\
\hline Height (cm) & $\begin{array}{l}177.4=5.6 \\
(169-190)\end{array}$ & $\begin{array}{l}177.7=6.5 \\
(167-1.09)\end{array}$ & $\begin{array}{c}165,1=4.2 \\
(188-176)\end{array}$ & $\begin{array}{c}166.5+8.1 \\
\langle 155-183\rangle\end{array}$ & $\begin{array}{l}171.7=8.5 \\
(165-180)\end{array}$ \\
\hline Weigre fogl & $\begin{array}{l}71,7=10.2 \\
686-100.7)\end{array}$ & $\begin{array}{l}81.7=14.9 \\
(592-1059)\end{array}$ & $\begin{array}{l}61,1=10.7 \\
{[43,-78,7]}\end{array}$ & $\begin{array}{l}66.6=103 \\
455.7-98.85\end{array}$ & $\begin{array}{l}70.3=137 \\
(43,1-106.91\end{array}$ \\
\hline BMI fegm ? & $\begin{array}{l}62.7-100.7) \\
227=2.0 \\
|20.1-27.9|\end{array}$ & $\begin{array}{l}(9.2 .2-106.9) \\
26,9=4.6 \\
(18.7-33.6)\end{array}$ & $\begin{array}{l}42.4+3.8 .8 \\
22.3-27.61\end{array}$ & $\begin{array}{l}(56.7-086) \\
24.1=3 E \\
\langle 18.0-29.5\rangle\end{array}$ & $\begin{array}{l}(43)-106.61 \\
23.6+3.7 \\
(17.3-33.9)\end{array}$ \\
\hline 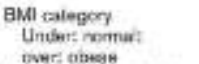 & $0: 11: 130$ & $0.5: 4: 3$ & $1: 7: 400$ & $0: 7: 5: 0$ & $1: 30: 14: 8$ \\
\hline $\begin{array}{l}\text { Lewe d actinty fige } \\
\text { modenate: lool }\end{array}$ & $8: 4: 0$ & 6:5:t & $4: 8: 0$ & $5: 7: 0$ & $23: 24: 1$ \\
\hline Footedness (bitt: riph) & $\mid: 11$ & 2:10 & $\alpha 12$ & $1: 11$ & $4: 44$ \\
\hline
\end{tabular}

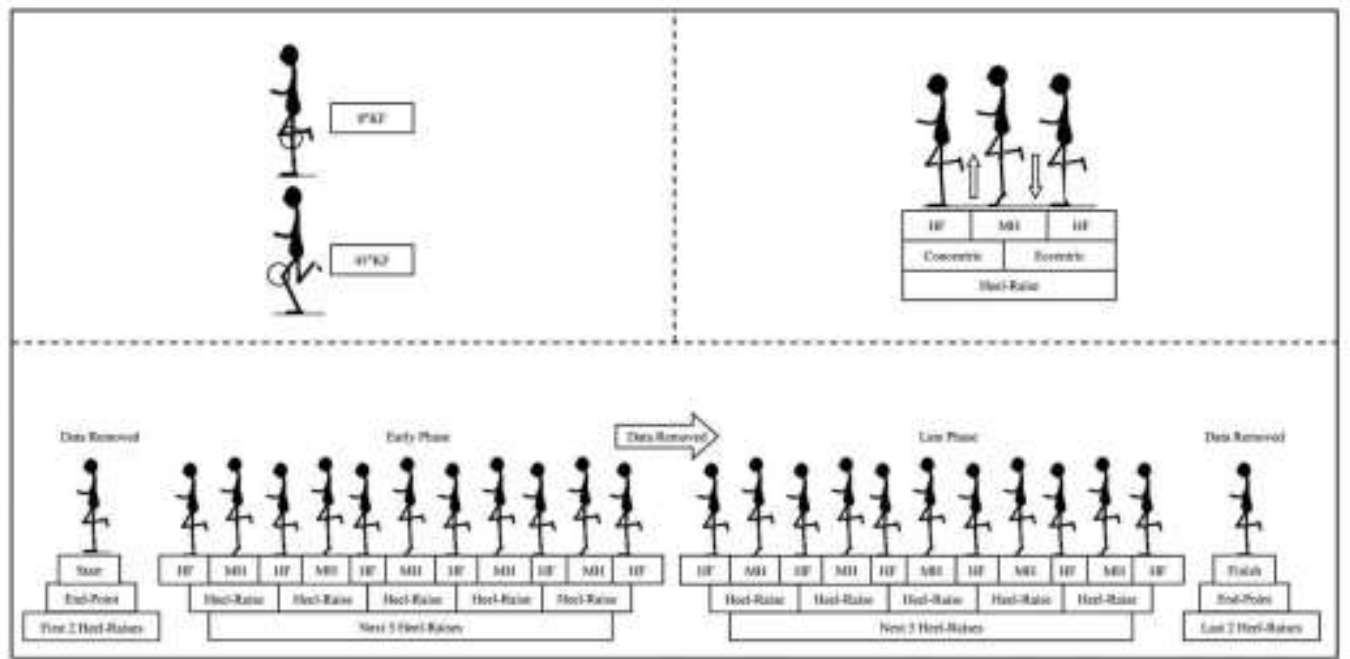

Figure 1. Representation of the $2 \mathrm{KF}$ angle positions (top left), concentric and eccentric plantar-flexion contractions (top right), and a complete heel-raise trial with the data reduction process (bottom). The $\mathrm{HF}$ and $\mathrm{MH}$ data points, end-point errors, and 5 heel raises extracted for analysis in the early and late phases are identified. KF = knee flexion; $\mathrm{HF}=$ heel to floor; $\mathrm{MH}=$ maximum heel-raise height.

Journal of Strength and Conditioning Research, Vol. 26, No. 11 (November 2012): pg. 3134-3147. DOI. This article is (C) Lippincott Williams \& Wilkins, Inc. and permission has been granted for this version to appear in e-

Publications@Marquette. Lippincott Williams \& Wilkins, Inc. does not grant permission for this article to be further copied/distributed or hosted elsewhere without the express permission from Lippincott Williams \& Wilkins, Inc. 
NOT THE PUBLISHED VERSION; this is the author's final, peer-reviewed manuscript. The published version may be accessed by following the link in the citation at the bottom of the page.

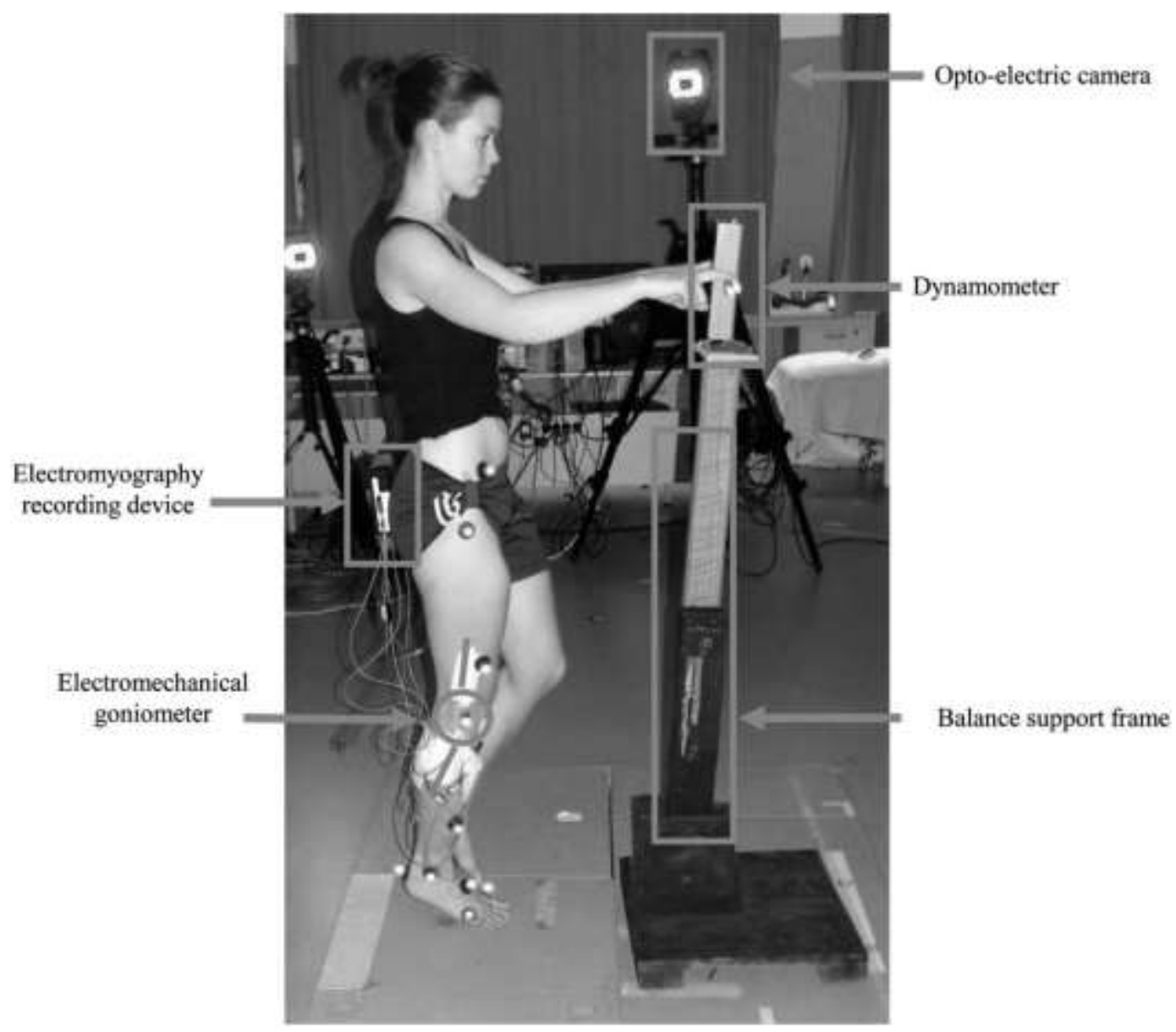

Figure 2. Subject during a heel raise performed in $0^{\circ} \mathrm{KF}$. Testing apparatus and instrumentation are identified. $\mathrm{KF}=$ knee flexion.

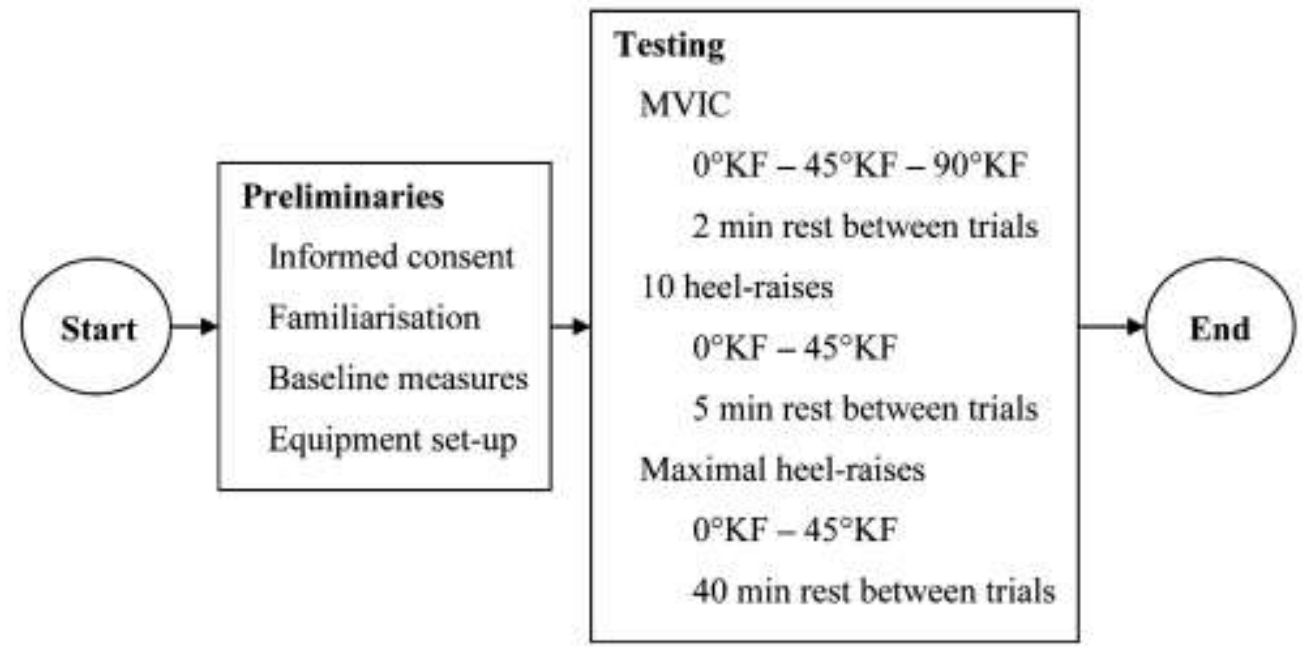

Figure 3. Experimental flow of the laboratory testing session for a subject. MVIC $=$ maximum voluntary isometric contraction; $\mathrm{KF}=$ knee flexion

Journal of Strength and Conditioning Research, Vol. 26, No. 11 (November 2012): pg. 3134-3147. DOI. This article is (C) Lippincott Williams \& Wilkins, Inc. and permission has been granted for this version to appear in e-

Publications@Marquette. Lippincott Williams \& Wilkins, Inc. does not grant permission for this article to be further copied/distributed or hosted elsewhere without the express permission from Lippincott Williams \& Wilkins, Inc. 
NOT THE PUBLISHED VERSION; this is the author's final, peer-reviewed manuscript. The published version may be accessed by following the link in the citation at the bottom of the page.

TABte 2. Means (and $95 \% \mathrm{Cl}$ of kinematic performance measures during heel raises to fatiguc by KF position and phase. $*+$

\begin{tabular}{|c|c|c|c|c|}
\hline \multirow{3}{*}{$\begin{array}{l}\text { KF position } \\
\text { Phase }\end{array}$} & \multicolumn{3}{|c|}{ Performance measure } & \multirow{3}{*}{$\begin{array}{l}\text { Outcome } \\
\text { Total (n) }\end{array}$} \\
\hline & \multirow{2}{*}{$\begin{array}{c}\text { Kneе } \\
\text { AAM (") }\end{array}$} & \multicolumn{2}{|c|}{ Heel raise } & \\
\hline & & Height $(\mathrm{mm}$ ) & Work (ग) & \\
\hline \multicolumn{5}{|l|}{$0^{\circ} \mathrm{KF}$} \\
\hline Early + late & $4.8[3.5,6.2]$ & $74.9[69.6,80.2]$ & $51.5[47.1,55.9]$ & $45.1[38.6,51.6]$ \\
\hline Eary & $4.8[3.6,6.1]$ & $87.3[81.8,93.1]$ & $60.0[55,2,64.8]$ & \\
\hline \multirow{2}{*}{\multicolumn{5}{|c|}{$45^{\circ} \mathrm{KF}$}} \\
\hline & & & & \\
\hline Early + late & $44.4[43.6,45.3]$ & $75.0[69.8,80.2]$ & $51.6[47.2,56.1]$ & $48.4[40.6,56.2]$ \\
\hline Early & $45.5[44.5,46.5]$ & $81.9[76.6,87,1]$ & $56.0[51.8,80.2]$ & \\
\hline Late & $44.9[43.7,46.2]$ & $63.9[57.9,69.9]$ & $44.1[39.3,48.9]$ & \\
\hline
\end{tabular}

${ }^{\circ} \mathrm{Cl}=$ confidence interval; $\mathrm{KF}=$ knee flexion; $\mathrm{AMM}=$ average angle maintaned.

tResults are from the analysis of 5 consecutive heed raises in the early phase and 5 consecutive heel raises in the late phase, except for outcomes $(a)$ calculated over the duration of testng. Data from the early and laie phases are reported oollect vely $(t)$ and separately.

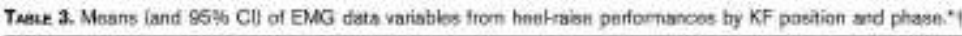

\begin{tabular}{|c|c|c|c|c|c|c|c|c|c|c|c|c|}
\hline \multirow{3}{*}{$\begin{array}{l}\text { KF position } \\
\text { Phesen }\end{array}$} & \multicolumn{4}{|c|}{ Anpitude (\%o MVKC) } & \multicolumn{4}{|c|}{$\mathrm{MF}\{\mathrm{He}]$} & \multicolumn{4}{|c|}{ MFNS $\left\{W^{-1} s^{-1}\right\}$} \\
\hline & \multicolumn{3}{|c|}{ TS muscis: } & \multirow[b]{2}{*}{ ATS } & \multicolumn{3}{|c|}{ TS muscke } & \multirow[b]{2}{*}{ ATS } & \multicolumn{3}{|c|}{ TS muscla } & \multirow[b]{2}{*}{ ATS } \\
\hline & $\$ S O L$ & GM & GL & & SOL & GM & $G L$ & & $\mathrm{SOL}$ & GM & GL & \\
\hline \multicolumn{13}{|l|}{$O \mathrm{KF}$} \\
\hline Eoty + & 23.4 & 23,7 & 214 & $22 \pi$ & 696 & 79.8 & 78,1 & 70.0 & -0.3 & $-\infty 0$ & -00 & -0.5 \\
\hline latn & $\{21,7,25, \not \mid$ & 1222.25 .31 & {$[20,0,22.97$} & {$[22.0 .28 .7]$} & {$[86.1,79.0 \mid$} & [958, 839] & {$[74.0,82.57$} & 752.7 .79 .91 & $\mid-0.4,-0.2$ & {$[-0.8,-0.5]$} & $1-0.7,-0.5$ & $1-0.6,-2.4$ \\
\hline Eialy & $\begin{array}{c}24.1 \\
|21.8 .264|\end{array}$ & $\begin{array}{c}26.8 \\
|234.20 .2|\end{array}$ & $\begin{array}{c}20.7 \\
(19.1,22.4]\end{array}$ & $\frac{23.6}{\mid 21.9 .25 .27}$ & $\begin{array}{c}73.8 \\
160.78 .98\end{array}$ & $\begin{array}{c}88.6 \\
\text { [82. } 846 !\end{array}$ & $\begin{array}{c}86.4 \\
100.3 .8251\end{array}$ & $\begin{array}{c}83.3 \\
792.67 .4\end{array}$ & & & & \\
\hline Latn & $\begin{array}{c}22.8 \\
\mid 20.2 .25 .11\end{array}$ & $112.7 .23 .6]$ & $\begin{array}{c}22.1 \\
{[10.5 .24 .6]}\end{array}$ & $\begin{array}{l}22.1 \\
{[20.4 .23 .9]}\end{array}$ & $\frac{85.3}{610.00}$ & $\begin{array}{c}71.1 \\
\mid 06.0 .751\end{array}$ & $\begin{array}{c}68.8 \\
65.4 .74 .21\end{array}$ & (65. 8.8 .0 & & & & \\
\hline \multicolumn{13}{|c|}{ 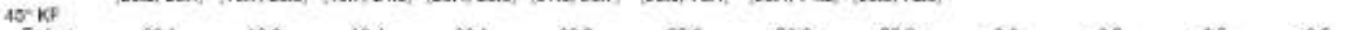 } \\
\hline Earty + & 20.1 & 19.8 & 184 & 22.1 & 630 & 87. 6 & $7 e \cdot 3$ & 75.8 & -as & -0.7 & -0.5 & -0.5 \\
\hline \multirow{2}{*}{ Eafly } & $|250.30 .2|$ & $\begin{array}{c}{[18.6 .21 .00]} \\
20.1\end{array}$ & $717.1,18.7]$ & {$[210.2311]$} & $\begin{array}{c}(60.265 .8) \\
68.1\end{array}$ & {$[83,1,920]$} & $724,80.2$ & $72.3,72.7]$ & $\{-0.4-0.3\}$ & {$[-0.8,-0.0]$} & {$[-0.6,-0.4]$} & $\mid-0.6,-0.4$ \\
\hline & $\begin{aligned} 29.1 \\
126.0,92.21\end{aligned}$ & $118.8,32.21$ & $\begin{array}{c}17.3 \\
{[16.5,10.1]}\end{array}$ & $\begin{array}{c}22.3 \\
20.8,23.91\end{array}$ & $\begin{array}{c}67.1 \\
(82.3218)\end{array}$ & $100.2,103.4$ & $\begin{array}{c}82,9 \\
77.2,89.8\end{array}$ & $\begin{array}{c}1720 \\
(780,86,0 !\end{array}$ & & & & \\
\hline \multirow[t]{2}{*}{ Late } & 27,0 & 18.3 & 183 & 21.9 & 029 & 78.3 & 70.6 & 69.5 & & & & \\
\hline & $120.1,30.8$ & $\{17.9,21.1]$ & {$[17,5,21,8]$} & {$[20.2,2 \times, 7]$} & {$[563,61,5]$} & [73.2. 1834] & $\cos 20,75,4 !$ & $\cos 0,720 i$ & & & & \\
\hline
\end{tabular}

Journal of Strength and Conditioning Research, Vol. 26, No. 11 (November 2012): pg. 3134-3147. DOI. This article is (C) Lippincott Williams \& Wilkins, Inc. and permission has been granted for this version to appear in e-

Publications@Marquette. Lippincott Williams \& Wilkins, Inc. does not grant permission for this article to be further copied/distributed or hosted elsewhere without the express permission from Lippincott Williams \& Wilkins, Inc. 
NOT THE PUBLISHED VERSION; this is the author's final, peer-reviewed manuscript. The published version may be accessed by following the link in the citation at the bottom of the page.

TABLE 4. Model intercept (bold) from stepwise regression analysis and estimates (and $95 \% \mathrm{Cl}$ ) of the effect of $\mathrm{KF}$, muscle, and age on MF (hertz) during heel raises to fatigue. ${ }^{*}+$ \$

\begin{tabular}{|c|c|c|c|}
\hline Effect & Comparison (reference) & Estimate $[95 \% \mathrm{Cl}]$ & $p$ \\
\hline Intercept & $\begin{array}{l}\text { (SOL } 0^{\circ} \mathrm{KF} \\
\text { early YA) }\end{array}$ & $76.1[70.2,82.0]$ & $<0.001$ \\
\hline \multirow[t]{3}{*}{ Muscle } & GM (SOL) & $10.0[1.8,18.2]$ & 0.003 \\
\hline & $\mathrm{GL}(\mathrm{SOL})$ & $9.8[2.2,17.4]$ & 0.002 \\
\hline & $\mathrm{GL}(\mathrm{GM})$ & $-0.2[-8.4,8.0]$ & 0.937 \\
\hline \multicolumn{4}{|c|}{$\mathrm{KF}$ on a TS muscle } \\
\hline SOL & $45^{\circ} \mathrm{KF}\left(0^{\circ} \mathrm{KF}\right)$ & $-6.4[-11.8,-1.1]$ & 0.003 \\
\hline GM & $45^{\circ} \mathrm{KF}\left(0^{\circ} \mathrm{KF}\right)$ & $7.7[2.3,13.0]$ & $<0.001$ \\
\hline $\mathrm{GL}$ & $45^{\circ} \mathrm{KF}\left(0^{\circ} \mathrm{KF}\right)$ & $-1.8[-7.1,3.6]$ & 0.572 \\
\hline \multicolumn{4}{|c|}{ Muscle in a KF position } \\
\hline \multirow{3}{*}{$45^{\circ} \mathrm{KF}$} & GM (SOL) & $24.1[15.9,32.4]$ & $<0.001$ \\
\hline & GL (SOL) & $14.5[7.1,21.9]$ & $<0.001$ \\
\hline & $\mathrm{GL}(\mathrm{GM})$ & $-9.7[-17.9,-1.4]$ & 0.003 \\
\hline \multicolumn{4}{|c|}{$\mathrm{KF}$ and muscle interaction } \\
\hline \multirow{3}{*}{$45^{\circ} \mathrm{KF}\left(0^{\circ} \mathrm{KF}\right)$} & $\mathrm{GM}(\mathrm{SOL})$ & $14.1[5.7,22.5]$ & $<0.001$ \\
\hline & $\mathrm{GL}(\mathrm{SOL})$ & $4.7[-2.1,11.4]$ & 0.108 \\
\hline & $\mathrm{GL}(\mathrm{GM})$ & $-9.4[-17.9,-1.0]$ & 0.003 \\
\hline \multicolumn{4}{|c|}{ Phase on a TS muscle } \\
\hline SOL & Late (early) & $-8.7[-13.9,-3.5]$ & $<0.001$ \\
\hline $\mathrm{GM}$ & Late (early) & $-17.9[-23.2,-12.6]$ & $<0.001$ \\
\hline $\mathrm{GL}$ & Late (early) & $-14.0[-19.3,-8.8]$ & $<0.001$ \\
\hline \multicolumn{4}{|c|}{ Muscle in a phase } \\
\hline \multirow[t]{3}{*}{ Late } & $\mathrm{GM}(\mathrm{SOL})$ & $0.8[-7.4,9.0]$ & 0.950 \\
\hline & $\mathrm{GL}(\mathrm{SOL})$ & $4.5[-2.9,11.9]$ & 0.314 \\
\hline & $\mathrm{GL}(\mathrm{GM})$ & $3.7[-4.6,11.9]$ & 0.385 \\
\hline \multicolumn{4}{|c|}{ Phase and muscle interaction } \\
\hline \multirow[t]{3}{*}{ Late (early) } & $\mathrm{GM}(\mathrm{SOL})$ & $-9.2[-17.4,-1.1]$ & 0.008 \\
\hline & $\mathrm{GL}(\mathrm{SOL})$ & $-5.3[-12.8,2.1]$ & 0.133 \\
\hline & $\mathrm{GL}(\mathrm{GM})$ & $3.9[-4.3,12.0]$ & 0.385 \\
\hline \multicolumn{4}{|c|}{ Age on a TS muscle } \\
\hline SOL & YA (MA) & $-4.7[-15.3,5.9]$ & 0.547 \\
\hline GM & YA (MA) & $5.4[-5.2,16.0]$ & 0.391 \\
\hline $\mathrm{GL}$ & YA (MA) & $-1.7[-12.3,8.9]$ & 0.879 \\
\hline \multicolumn{4}{|l|}{ Muscle in MA } \\
\hline \multirow[t]{3}{*}{$45^{\circ} \mathrm{KF}$} & $\mathrm{GM}(\mathrm{SOL})$ & $20.1[11.9,28.4]$ & $<0.001$ \\
\hline & $\mathrm{GL}(\mathrm{SOL})$ & $12.8[5.1,20.5]$ & $<0.001$ \\
\hline & $\mathrm{GL}(\mathrm{GM})$ & $-7.3[-15.6,0.9]$ & 0.055 \\
\hline \multicolumn{4}{|c|}{ Age and muscle interaction } \\
\hline \multirow[t]{3}{*}{ YA (MA) } & GM (SOL) & $10.1[1.9,18.2]$ & 0.004 \\
\hline & $\mathrm{GL}(\mathrm{SOL})$ & $3.0[-5.0,10.9]$ & 0.547 \\
\hline & $\mathrm{GL}(\mathrm{GM})$ & $-7.1[-15.3,1.1]$ & 0.055 \\
\hline
\end{tabular}

"Comparison (reference) $=$ comparison reference; $\mathrm{Cl}=$ confidence interval; $\mathrm{KF}=$ knee flexion; TS = triceps surae; $E M G=$ electromyography; $M F=$ median frequency; $S O L=$ soleus: $\mathrm{GM}=$ gastrocnemius medial is; $\mathrm{GL}=$ gastrocnemius lateralis; $Y \mathrm{~A}=$ younger-aged group of 18 25 years; $M A=$ middle aged group of $35-45$ years.

Estimates are derived from the regression model with $\mathrm{SOL}, 0^{\circ} \mathrm{KF}$, early phase, and middle: aged group as reference conditions, and $95 \% \mathrm{Cl}$ and $p$ values are adjusted using the Westfall method.

fLevels of significance $(\rho)$ are for the difference between 2 conditions with the reference in parentheses.

Journal of Strength and Conditioning Research, Vol. 26, No. 11 (November 2012): pg. 3134-3147. DOI. This article is @ Lippincott Williams \& Wilkins, Inc. and permission has been granted for this version to appear in e-

Publications@Marquette. Lippincott Williams \& Wilkins, Inc. does not grant permission for this article to be further copied/distributed or hosted elsewhere without the express permission from Lippincott Williams \& Wilkins, Inc. 
NOT THE PUBLISHED VERSION; this is the author's final, peer-reviewed manuscript. The published version may be accessed by following the link in the citation at the bottom of the page.

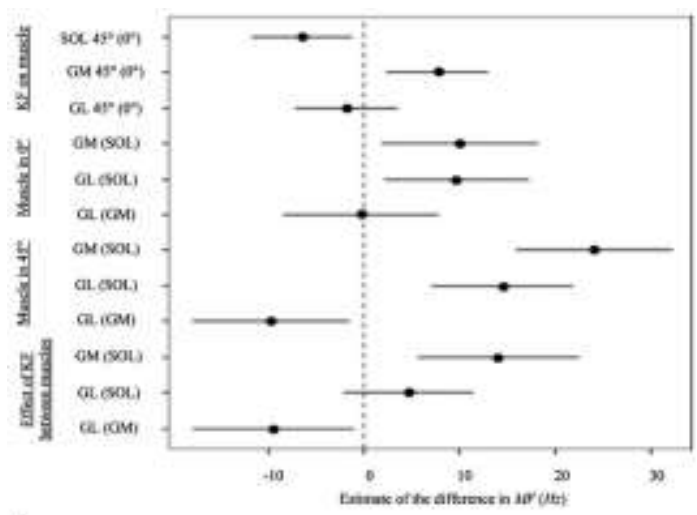

A

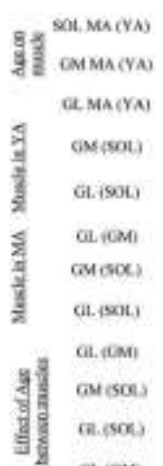

$\mathrm{C}$

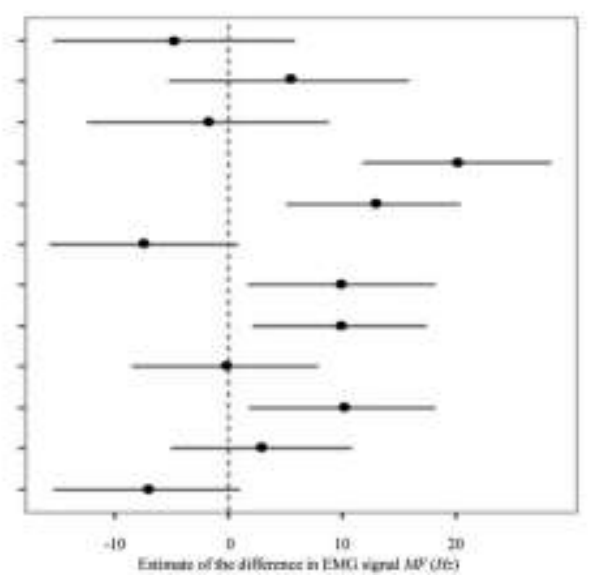

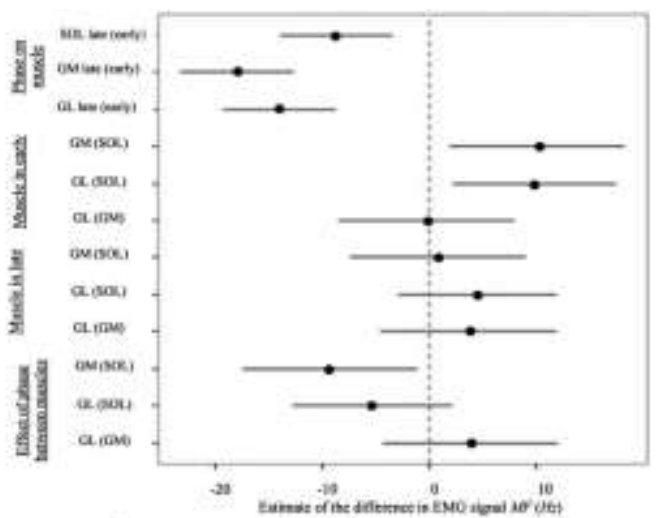

B

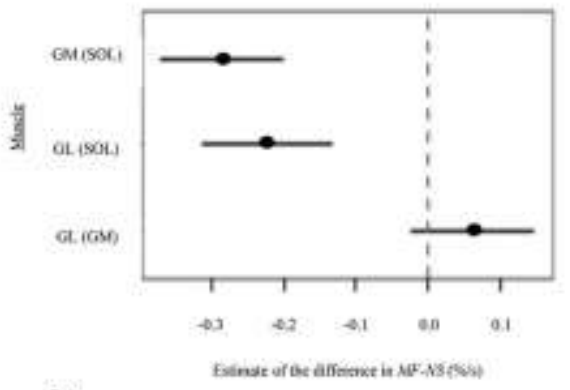

D

Figure 4. Estimates of the differences in MF (A-C) and MF-NS (D) between TS muscles. Interaction effects of muscle with $\mathrm{KF}(\mathrm{A})$, phase $(B)$, and age $(C)$ are represented. Full circles are means $(\bullet)$, and black lines are $95 \%$ confidence intervals $(-)$. The reference used for comparison is in parentheses. Comparison (reference) $=$ comparison reference; $\mathrm{EMG}=$ electromyography; $\mathrm{TS}=$ triceps surae; $\mathrm{MF}=$ median frequency; $\mathrm{KF}=$ knee flexion; $\mathrm{SOL}=$ soleus; $\mathrm{GM}=$ gastrocnemius medialis; $\mathrm{GL}=$ gastrocnemius lateralis; $Y A=$ younger-aged group of 18-25 years; $M A=$ middle-aged group of 35-45 years; MF-NS = median frequency normalized slope. A). Estimate of the difference in MF between one TS muscle in a given KF position and another muscle and the other KF position during heel raises to fatigue. The effect of KF between muscles is the change in MF from $0^{\circ} \mathrm{KF}$ to $45^{\circ} \mathrm{KF}$ in 1 muscle compared with another muscle. B) Estimates of the differences in MF between 1 TS muscle in a given phase and another muscle and the other phase during heel raises to fatigue. The effect of phase between muscles is the shift in MF from early to late in 1 muscle compared with another muscle. C) Estimates of the differences in MF between 1 TS muscle in a given age group and another muscle and the other age group during heel raises to fatigue. The effect of age between muscles is the change in MF from YA to MA in 1 muscle compared with another muscle. D) Estimates of the differences in MF-NS between 1 TS muscle and another muscle during heel raises to fatigue. 
NOT THE PUBLISHED VERSION; this is the author's final, peer-reviewed manuscript. The published version may be accessed by following the link in the citation at the bottom of the page.

TABLE 5. Model intercept (bold) from stepwise regression analysis and estimates (and $95 \% \mathrm{Cl}$ ) of the effect of muscle on MF-NS $\left(\% \cdot \mathrm{s}^{-1}\right.$ ) during heel raises to fatigue. ${ }^{*}+\ddagger$

\begin{tabular}{lcrr}
\hline Effect & Comparison (reference) & Estimate $(95 \% \mathrm{Cl})$ & $p$ \\
\hline Intercept & (SOL) & $-\mathbf{0 . 3}[\mathbf{- 0 . 4}, \mathbf{- 0 . 2}]$ & $<\mathbf{0 . 0 0 1}$ \\
Muscle & GM (SOL) & $-0.3[-0.4,-0.2]$ & $<0.001$ \\
& GL (SOL) & $-0.2[-0.3,-0.1]$ & $<0.001$ \\
& GL (GM) & $-0.06[-0.02,0.1]$ & 0.088 \\
\hline
\end{tabular}

"Comparison (reference) $=$ comparison reference; $\mathrm{Cl}=$ confidence interval; $\mathrm{EMG}=$ electromyography; MF-NS = median frequency normalized slope; $\mathrm{SOL}=$ soleus; $\mathrm{GM}=$ gastrocnemius medialis; $\mathrm{GL}=$ gastrocnemius lateralis.

$\dagger$ Estimates are derived from the regression model with $\mathrm{SOL}$ as reference condition, and $95 \% \mathrm{Cl}$ and $\rho$ values are adjusted using the Westfall method.

fLevels of significance $(p)$ are for the difference between 2 conditions with the reference in parentheses.

Journal of Strength and Conditioning Research, Vol. 26, No. 11 (November 2012): pg. 3134-3147. DOI. This article is (C) Lippincott Williams \& Wilkins, Inc. and permission has been granted for this version to appear in e-

Publications@Marquette. Lippincott Williams \& Wilkins, Inc. does not grant permission for this article to be further copied/distributed or hosted elsewhere without the express permission from Lippincott Williams \& Wilkins, Inc. 